\title{
Relation between isovolumic relaxation period of left ventricle and pulmonary artery pressure in d-transposition of the great arteries ${ }^{\star}$
}

\author{
FRANCOOIS BOURLON, JEAN-CLAUDE FOURON, JUAN BATTLE-DIAZ, \\ GILLES DUCHARME, ANDRE DAVIGNON
}

From the Section of Cardiology, Departments of Pediatrics and Pediatric Research, Ste fustine Hospital and University of Montreal, Montreal, Quebec, Canada

SUMMARY The study aimed to identify the best echocardiographic time interval (systolic or diastolic) for assessing pulmonary artery pressure in children with d-transposition of the great arteries. Echocardiograms were performed in 21 children with d-transposition of the great arteries within 48 hours of cardiac catheterisation. None of the children had had a Mustard procedure. Twenty-four recordings were obtained, three patients having been catheterised twice. Highest correlations were found for the ratio of the isovolumic relaxation time over the ejection time of the left ventricle (IRT/LVET) to the systolic pressure in the pulmonary artery and also between IRT/LVET and the difference between mean pulmonary artery pressure and mean left atrial pressure. All patients with a negative IRT/LVET ratio had a pulmonary systolic pressure lower than $35 \mathrm{mmHg}$ and a mean pulmonary pressure lower than $25 \mathrm{mmHg}$. In patients with d-transposition, a negative IRT/LVET ratio appears to be a reliable indication of normal pressure in the pulmonary circulation. Serial echocardiographic studies for the follow-up of patients with d-transposition should include measurement of the time of relaxation of the left ventricle.

The value of echocardiography in the assessment of the pulmonary vascular bed has been shown by several investigators using systolic time intervals (STI). Most studies have shown good correlation between pre-ejection period (PEP), 1 pre-ejection period over ejection time (PEP/ET),$^{23}$ isometric contraction time ${ }^{4}$ of the right ventricle, and the pulmonary pressure of patients with normally related great arteries. More recently, Gutgesel1 ${ }^{5}$ has used the ratio PEP/ET of the left ventricle to estimate pulmonary pressure in d-transposition of the great arteries.

Although the isovolumic relaxation time (IRT) of the right ventricle has long been shown to be a good index of pulmonary pressure,$^{6-8}$ the value of IRT of the left ventricle in d-transposition of the great arteries has not been studied. In addition, previous measurements of IRT in adults have involved the use of apex cardiograms which are difficult to obtain in small children.

*Work supported in part by the Macdonald Stewart Foundation, the Canadian Heart Foundations, and La Fondation JustineLacoste-Beaubien.

Received for publication 20 July 1979
Because of the clinical importance of establishing reliable criteria for evaluation of pulmonary artery pressure in d-transposition ${ }^{9}$ and the ease with which mitral and pulmonary valve echograms are obtained in this condition, we have compared the reliability of IRT of the left ventricle to that of STI in the assessment of the pulmonary vascular bed.

\section{Subjects and methods}

Echocardiograms were performed in 21 children with d-transposition within 48 hours of a cardiac catheterisation. Twenty-four recordings were obtained, three patients having been catheterised twice. Patients ranged in age from 1 day to 5.5 years (median age: 21.5 months). As the peculiar variations of pressure in the newly formed left atrium ${ }^{10}$ might influence the time of opening of the mitral valve, patients with an intra-atrial baffle (Mustard procedure) were excluded from the study. They will form the subject of another report. Six patients had an associated ventricular septal defect, four had pulmonary stenosis (gradients greater than 
$15 \mathrm{mmHg}$ ), and five had ventricular septal defect and pulmonary stenosis. Patients older than 3 months were premedicated before cardiac catheterisation with a standard mixture of meperidine, promethazine, and chlorpromazine. ${ }^{11}$ Pulmonary artery pressure was recorded in all patients before angiography.

Echocardiograms were recorded simultaneously with an electrocardiogram on a Smith Kline Ekoline 20A coupled with a Honeywell fibreoptic recorder (model 1856) or a Cambridge multichannel physiological recorder. Tracings were obtained at a paper speed of $100 \mathrm{~mm} / \mathrm{s}$ with time lines at $40 \mathrm{~ms}$ allowing measurements to be made to the nearest $5 \mathrm{~ms}$ or better. ${ }^{12}$ Aerotech $5 \mathrm{MHz}$ unfocused and $3.5 \mathrm{MHz}$ focused transducers were used, according to the size of the patient. Left ventricular time intervals were calculated according to the criteria previously published by Hirschfeld and co-workers. ${ }^{2}$ The pre-ejection period was measured from the onset of ventricular depolarisation (beginning of the $Q$ wave on the electrocardiogram) to the opening of the pulmonary valve. The ejection time was measured from opening to closure of the pulmonary valve. Isovolumic contraction time was taken as the difference between $\mathrm{QP}_{\mathrm{o}}(\mathrm{Q}$ to pulmonary valve opening) and $Q M_{c}(Q$ to mitral valve closure). Isovolumic relaxation time was defined as the difference between $Q M_{0}$ ( $Q$ to mitral valve opening) and $Q P_{c}$ ( $Q$ to pulmonary valve closure) (Fig. 1). Mitral opening was defined as the point where anterior and posterior mitral leaflets separated (point D) on the echocardiogram. All measurements were performed on cardiac cycles
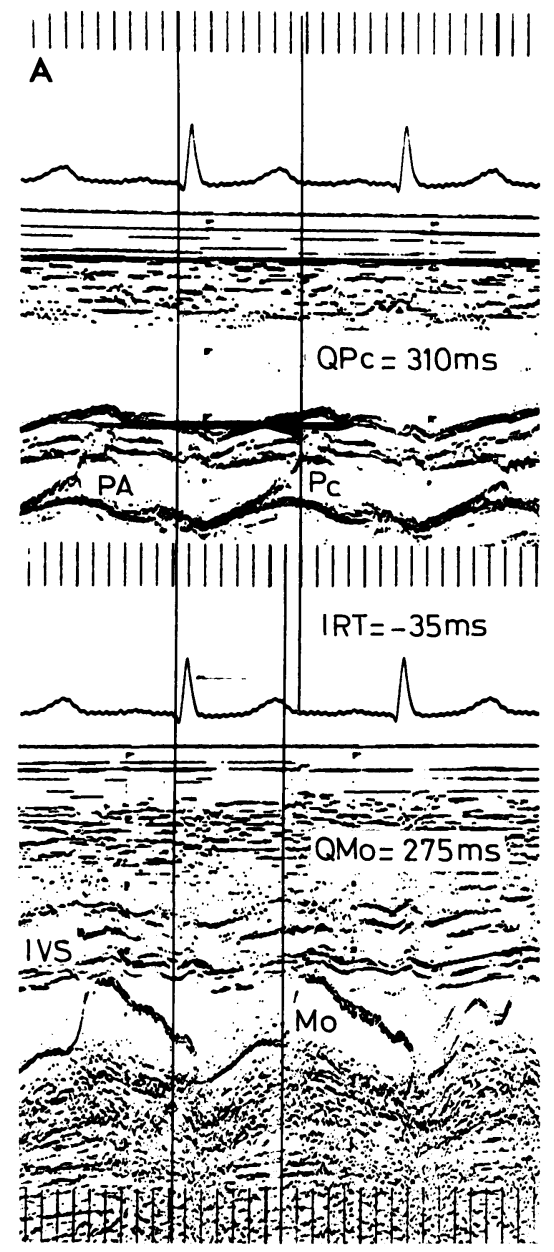

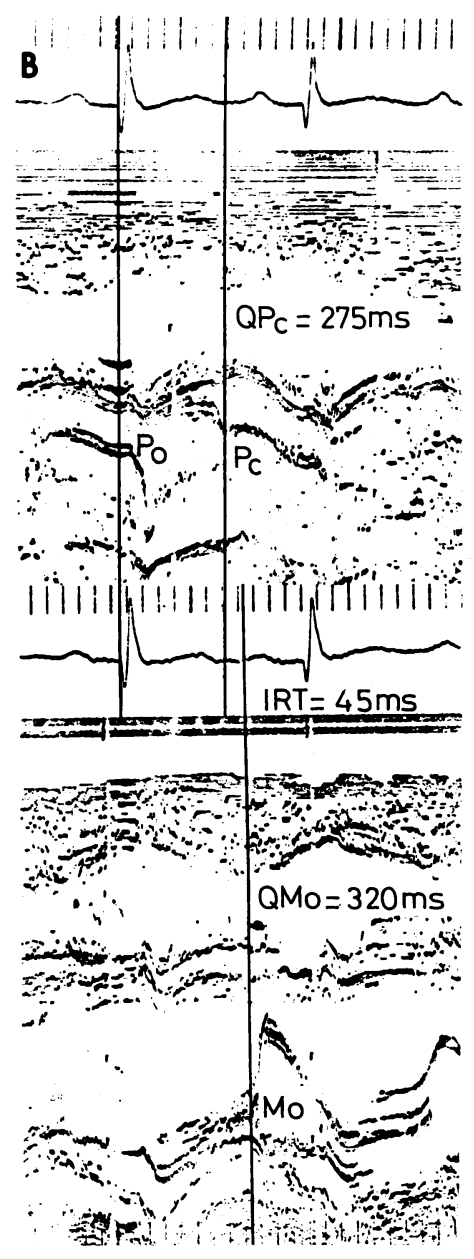

Fig. 1 Echocardiograms of pulmonary and mitral valves of two children with d-transposition. Panel A demonstrates a negative $I R T$ and panel $\mathrm{B}$ a positive IRT. $P A$, pulmonary artery; IVS, interventricular septum;

$P_{o}$, opening of pulmonary valve; $Q P_{c}$, interval from the beginning of the $Q$ wave to closure of pulmonary valve; $Q M_{o}$, interval from the beginning of the $Q$ wave to opening of mitral valve; $I R T=Q M_{o}-Q P_{c}$ 
Table 1 Haemodynamic and echocardiographic data

\begin{tabular}{|c|c|c|c|c|c|c|c|c|c|c|c|}
\hline Age & $\begin{array}{l}\text { Associated } \\
\text { lesions }\end{array}$ & $\begin{array}{l}P A S P \\
(m m H g)\end{array}$ & $\begin{array}{l}P A D P \\
(m m H g)\end{array}$ & $\begin{array}{l}\overline{P A} \\
(m m H g)\end{array}$ & $\begin{array}{l}\overline{P A-L A} \\
(m m H g)\end{array}$ & $\overline{P A} \overline{A o}$ & $\begin{array}{l}\text { PEP/ } \\
\text { LVET }\end{array}$ & $\begin{array}{l}I C T \\
(m s)\end{array}$ & $\begin{array}{l}I C T / \\
L V E T\end{array}$ & $\begin{array}{l}I R T \\
(m s)\end{array}$ & $\begin{array}{l}\text { IRT/ } \\
L V E T\end{array}$ \\
\hline $\begin{array}{l}5 \mathrm{d \star} \\
19 \mathrm{mth} \\
26 \mathrm{mth} \\
30 \mathrm{mth} \\
2 \mathrm{d \dagger} \\
33 \mathrm{mth} \\
27 \mathrm{mth} \\
17 \mathrm{mth} \\
7 \mathrm{mth} \\
2 \mathrm{mth} \\
24 \mathrm{mth} \\
24 \mathrm{mth} \\
12 \mathrm{mth} \\
1 \mathrm{~d} \\
30 \mathrm{mth} \\
30 \mathrm{mth} \\
66 \mathrm{mth} \\
3 \mathrm{mth} \dagger \\
30 \mathrm{mth} \\
46 \mathrm{mth} \\
6 \mathrm{mth} \\
2 \mathrm{d \dagger} \\
8 \mathrm{mth} \dagger \\
66 \mathrm{mth}\end{array}$ & $\begin{array}{l}\text { VSD } \\
\text { VSD } \\
\text { PS } \\
\text { PS } \\
\text { VSD } \\
\\
\text { VSD } \\
\text { VSD } \\
\text { PS } \\
\text { VSD PS } \\
\text { VSD PS } \\
\text { VSD PS } \\
\text { PS } \\
\text { VSD PS } \\
\text { VSD } \\
\text { PS } \\
\text { VSD PS }\end{array}$ & $\begin{array}{l}49 \\
23 \\
21 \\
22 \\
45 \\
20 \\
22 \\
25 \\
22 \\
61 \\
36 \\
95 \\
87 \\
68 \\
22 \\
30 \\
29 \\
17 \\
29 \\
30 \\
75 \\
60 \\
11 \\
32\end{array}$ & $\begin{array}{r}26 \\
13 \\
11 \\
10 \\
16 \\
7 \\
10 \\
12 \\
10 \\
28 \\
11 \\
62 \\
46 \\
37 \\
10 \\
17 \\
17 \\
6 \\
11 \\
14 \\
29 \\
5 \\
2 \\
12\end{array}$ & $\begin{array}{r}33 \\
15 \\
16 \\
15 \\
32 \\
11 \\
13 \\
17 \\
14 \\
46 \\
20 \\
77 \\
65 \\
41 \\
16 \\
22 \\
23 \\
12 \\
20 \\
17 \\
47 \\
31 \\
7 \\
20\end{array}$ & $\begin{array}{r}23 \\
8 \\
11 \\
6 \\
27 \\
6 \\
5 \\
10 \\
4 \\
34 \\
14 \\
71 \\
57 \\
35 \\
6 \\
19 \\
2 \\
10 \\
15 \\
9 \\
39 \\
26 \\
5 \\
13\end{array}$ & $\begin{array}{l}0.58 \\
0.23 \\
0.20 \\
0.25 \\
0.63 \\
0.14 \\
0.19 \\
0.26 \\
0.18 \\
0.77 \\
0.33 \\
1.13 \\
1.05 \\
0.077 \\
0.26 \\
0.29 \\
0.32 \\
0.20 \\
0.32 \\
0.24 \\
0.77 \\
0.58 \\
0.11 \\
0.32\end{array}$ & $\begin{array}{l}0.23 \\
0.25 \\
0.21 \\
0.14 \\
0.29 \\
0.16 \\
0.17 \\
0.15 \\
0.20 \\
0.21 \\
0.20 \\
0.40 \\
0.34 \\
0.30 \\
0.25 \\
0.19 \\
0.18 \\
0.30 \\
0.14 \\
0.35 \\
0.30 \\
0.25 \\
0.24 \\
0.16\end{array}$ & $\begin{array}{c}-15 \\
-5 \\
0 \\
0 \\
15 \\
5 \\
-30 \\
20 \\
0 \\
5 \\
0 \\
40 \\
30 \\
20 \\
30 \\
5 \\
\star 5 \\
10 \\
20 \\
20 \\
10 \\
0 \\
0 \\
10\end{array}$ & $\begin{array}{r}-0.08 \\
-0.02 \\
0.00 \\
0.00 \\
0.08 \\
0.02 \\
0.13 \\
0.07 \\
0.00 \\
0.02 \\
0.00 \\
0.20 \\
0.15 \\
0.10 \\
0.11 \\
0.02 \\
0.02 \\
0.05 \\
0.07 \\
0.09 \\
0.05 \\
0.00 \\
0.00 \\
0.01\end{array}$ & $\begin{array}{r}10 \\
-25 \\
10 \\
-20 \\
10 \\
-15 \\
-20 \\
-25 \\
-20 \\
25 \\
20 \\
40 \\
45 \\
30 \\
-35 \\
5 \\
-30 \\
-15 \\
-10 \\
-10 \\
20 \\
10 \\
-20 \\
-10\end{array}$ & $\begin{array}{r}0.05 \\
-0.11 \\
0.04 \\
-0.07 \\
0.05 \\
-0.05 \\
-0.08 \\
-0.09 \\
-0.07 \\
0.12 \\
0.10 \\
0.20 \\
0.22 \\
0.15 \\
-0.13 \\
0.02 \\
-0.09 \\
-0.08 \\
0.04 \\
-0.04 \\
0.10 \\
0.06 \\
-0.10 \\
-0.03\end{array}$ \\
\hline
\end{tabular}

$\star$ Catheterised twice. † Catheterised twice.

VSD, ventricular septal defect; PS, pulmonary stenosis; PASP, pulmonary artery systolic pressure; PADP, pulmonary artery diastolic pressure; $\overline{\mathrm{PA}}$, mean pulmonary artery pressure; $\overline{\mathrm{LA}}$, mean left atrial pressure; $\overline{\text { Ao, }}$ mean aortic pressure; PEP, pre-ejection period; LVET, left ventricle ejection time; ICT, isovolumic contraction time; IRT, isovolumic relaxation time.

of equal $R R$ intervals. Each value represented the average of at least five different complexes. All infants were either sleeping or resting quietly at the time of the echocardiogram.

To determine the best regression equations relating pulmonary pressure to STI and IRT, we used the 'stepwise multiple regression' technique. ${ }^{13}$ This technique permits the inclusion of the echocardiographic variables that significantly increase the regression coefficient. The validity of the regression equations was assessed by Fisher's $F$ test.

\section{Results}

Measurements obtained are given in Table 1. Correlation coefficients relating the left ventricular STI and IRT to haemodynamic data are shown in Table 2. IRT showed a better correlation than STI with all haemodynamic indices studied. Still stronger correlations were found when the ratio IRT/LVET was used.

The relation between IRT/LVET and the pulmonary systolic and mean pressures are shown in Fig. $2 A$ and B. Negative IRT and IRT/LVET values were observed in 13 cases and were always associated with a peak pulmonary pressure of less than $35 \mathrm{mmHg}$ and a mean pressure of less than $25 \mathrm{mmHg}$. The best planar and multiple regression equations are given in Table 3.
There was no relation between left ventricular systolic pressure and IRT.

\section{Discussion}

In d-transposition of the great arteries, IRT of the left ventricle is the time between closure of the pulmonary valve and opening of the mitral valve. As in subjects without d-transposition, ${ }^{6714}$ IRT should be influenced by: the level of pulmonary artery pressure at the time of closure of the pulmonary valve, left atrial pressure, heart rate, and downslope of left ventricular pressure, this last factor being dependent on preload, afterload, contractility, and compliance of the left ventricle..$^{16}$

In pulmonary hypertension, the IRT will lengthen because pressure in the ventricle will fall from a higher point before reaching the left atrial level. The $\mathrm{Q}-\mathrm{P}_{\mathrm{c}}$ interval (from the beginning of the

Table 2 Correlation matrix

\begin{tabular}{llllll}
\hline & $\begin{array}{l}\text { PEP/ } \\
\text { LVET }\end{array}$ & ICT & $\begin{array}{l}\text { ICT/ } \\
\text { LVET }\end{array}$ & IRT & $\begin{array}{l}\text { IRT/ } \\
\text { LVET }\end{array}$ \\
\hline PASP & 0.64 & 0.45 & 0.53 & 0.87 & 0.90 \\
PADP & 0.63 & 0.52 & 0.60 & 0.76 & 0.79 \\
PAMP & 0.64 & 0.51 & 0.59 & 0.84 & 0.87 \\
$\overline{\text { PA- }} \overline{\text { LA }}$ & 0.68 & 0.53 & 0.62 & 0.88 & 0.90 \\
$\overline{\text { PA } / \overline{\text { Ao }}}$ & 0.64 & 0.48 & 0.56 & 0.86 & 0.89 \\
\hline
\end{tabular}

See footnote to Table 1 for explanation of abbreviations. 


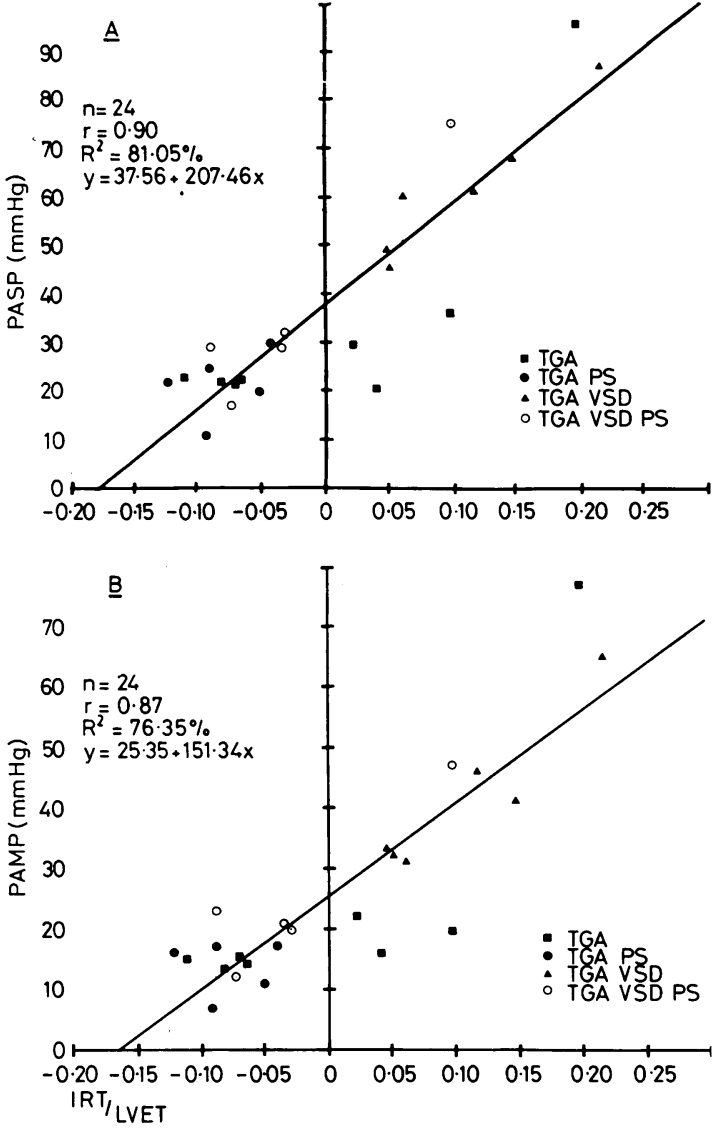

Fig. 2 Relation between IRT/LVET, PASP (A), and $P A M P$ (B). PASP, pulmonary artery systolic pressure; $P A M P$, pulmonary artery mean pressure; IRT, isovolumic relaxation time; LVET, left ventricle ejection time.
Q wave to closure of the pulmonary valve) by itself does not influence the duration of the fall of ventricular pressure ${ }^{6-8}$. Therefore, conditions delaying closure of the pulmonary valve such as pulmonary stenosis or ventricular conduction delay should not interfere directly with IRT.

An increase in left atrial pressure causes the mitral valve to open early and thereby shortens IRT. ${ }^{17}$ In patients with d-transposition of the great arteries and high pulmonary vascular resistance, raised pulmonary pressure should work together with low left atrial pressure to increase IRT. The reverse is true in patients with low pulmonary resistance and high atrial pressure. In d-transposition, since most patients have a large atrial septal defect, variations of left atrial pressure secondary to variations of pulmonary blood flow should be smaller. In fact, the correlation coefficient was only slightly higher for IRT when the left atrial mean pressure was subtracted from the pulmonary artery mean pressure (Table 2).

We found a weak correlation $(r=-0.46)$ between IRT and heart rate, as has been found by others in subjects without d-transposition ${ }^{15-18}$ and in experimental studies in dogs. ${ }^{17}$

The influence of the downslope of left ventricular pressure on IRT is more difficult to evaluate. In dogs, experimental hypertrophy of the right ventricle induced by pulmonary artery banding resulted in a decreased right ventricular contractility and compliance. ${ }^{19}$ Increased afterload, decreased preload, and left ventricular contractility have also been found to prolong IRT. Drugs can also influence IRT by acting on myocardial contractility. ${ }^{18}$ The relative importance of these factors on IRT, through their influence on left myocardial con-

Table 3 Regression equations

\begin{tabular}{|c|c|c|c|c|c|}
\hline Variable & $\begin{array}{l}\text { Type of } \\
\text { regression }\end{array}$ & Regression equation & $R^{2} \%$ & $s$ & Fisher's $F$ test \\
\hline PASP (mmHg) & $\begin{array}{l}\text { Multiple } \\
\text { Planar }\end{array}$ & $\begin{aligned}(\text { PASP })= & 22.62+638.70(\text { IRT } / \text { LVET })-2.08(\text { IRT })+164.90 \\
& (\text { PEP } / \text { LVET })^{2} \\
(\text { PASP })= & 37.56+207.46(\text { IRT } / \text { LVET })\end{aligned}$ & $\begin{array}{l}90 \cdot 3 \\
81 \cdot 1\end{array}$ & $\begin{array}{r}7 \cdot 81 \\
10 \cdot 42\end{array}$ & $\begin{array}{l}62.34 \quad \mathrm{P}<0.005 \\
94.12 \mathrm{P}<0.005\end{array}$ \\
\hline ' & Multiple & $($ PADP $)=12 \cdot 69+76 \cdot 31($ IRT $/$ LVET $)+784 \cdot 13(\text { ICT } / \text { LVET })^{2}$ & $83 \cdot 3$ & $6 \cdot 03$ & $52.37 \mathrm{P}<0.005$ \\
\hline PADP (mmHg) & Planar & $(\mathrm{PADP})=11.03+65.67(\mathrm{IRT} / \mathrm{LVET})+620.52(\mathrm{IRT} / \mathrm{LVET})^{2}$ & $80 \cdot 0$ & 8.01 & $25.12 \mathrm{P}<0.005$ \\
\hline PAMP (mmHg) & $\begin{array}{l}\text { Multiple } \\
\text { Planar }\end{array}$ & $\begin{aligned}(\text { PAMP })= & 19.30+361.23(\text { IRT } / \text { LVET })+613.49(\text { ICT } / \text { LVET })^{2} \\
& -1.06(\text { IRT }) \\
(\text { PAMP })= & 25.35+151 \cdot 34(\text { IRT } / \text { LVET })\end{aligned}$ & $\begin{array}{l}89 \cdot 2 \\
76 \cdot 4\end{array}$ & $\begin{array}{l}6 \cdot 21 \\
7 \cdot 88\end{array}$ & $\begin{array}{l}54.88 \quad \mathrm{P}<0.005 \\
46.91 \mathrm{P}<0.005\end{array}$ \\
\hline \multirow{2}{*}{$\overline{\mathrm{PA}}-\overline{\mathrm{LA}}(\mathrm{mmHg})$} & Multiple & $(\overline{\mathrm{PA}}-\overline{\mathrm{LA}})=14 \cdot 30+125 \cdot 46(\mathrm{IRT} / \mathrm{LVET})+690 \cdot 07(\mathrm{ICT} / \mathrm{LVET})^{2}$ & $90 \cdot 8$ & $5 \cdot 57$ & $103.89 \mathrm{P}<0.005$ \\
\hline & Planar & $(\overline{\mathrm{PA}}-\overline{\mathrm{LA}})=18.03+155.21(\mathrm{IRT} / \mathrm{LVET})$ & $80 \cdot 7$ & $6 \cdot 68$ & $68.90 \mathrm{P}<0.005$ \\
\hline$\overline{\mathrm{PA}} / \overline{\mathrm{Ao}}$ & $\begin{array}{l}\text { Multiple } \\
\text { Planar }\end{array}$ & $\begin{aligned}(\overline{\mathrm{PA}} / \overline{\mathrm{AO}})= & 0.09+8.12(\mathrm{IRT} / \mathrm{LVET})-0.03(\mathrm{IRT})+1.06 \\
(\overline{\mathrm{PA}} / \overline{\mathrm{AO}})= & 0.41+2.54(\mathrm{IRT} / \mathrm{LVET})\end{aligned}$ & $\begin{array}{l}888 \cdot 1 \\
78 \cdot 8\end{array}$ & $\begin{array}{l}0 \cdot 11 \\
0 \cdot 11\end{array}$ & $\begin{array}{l}62.81 \quad P<0.005 \\
49.36 \quad P<0.005\end{array}$ \\
\hline
\end{tabular}

See footnote to Table 1 for explanation of abbreviations. $\mathrm{R}_{\%}^{2} \%$, percentage of the variation explained; $s$, standard deviation of residuals. 
tractility, obviously cannot be determined in the group of patients studied. One would think that patients with d-transposition of the great arteries and pulmonary stenosis would have hypertrophic and 'non compliant' left ventricles with a prolonged IRT. However, this effect, if present, does not seem to be significant enough to change, in our group of patients, the correlation between IRT/LVET ratio and the pulmonary artery pressure.

A negative IRT was found in most cases of dtransposition of the great arteries with normal pulmonary pressure. Echocardiographic identification of the point of opening of the mitral valve could in part explain this finding. Pohost et al. ${ }^{20}$ in dogs and Rubenstein et al. ${ }^{21}$ in humans have distinguished point $\mathrm{D}$ and point $\mathrm{D}^{\prime}$; point $\mathrm{D}$ located at the separation of anterior and posterior mitral leaflets and point $D^{\prime}$ marking the onset of the rapid anterior movement of the mitral valve. This latter point correlated better with haemodynamic indicators of mitral valve opening defined as the crossover point between left atrial and ventricular pressures. However, more recently Tsakiris et al. ${ }^{22}$ showed with dogs that mitral valve opening consistently preceded the diastolic crossover point. Furthermore, in children, the distinction between point $\mathrm{D}$ and $\mathrm{D}^{\prime}$ is difficult, probably because of the rapid heart rate and of the high velocity of mitral valve opening. For these reasons, we have taken the point of separation of anterior and posterior mitral leaflets as representing opening of the valve. The prolonged "hang-out" time of the pulmonary valves in cases of d-transposition with low vascular resistance and increased pulmonary flow could also be put forward to explain the negative IRT in these patients.

Higher correlations appear to exist between pulmonary artery pressure and diastolic rather than systolic time intervals, the highest correlation coefficient being found between pulmonary artery systolic pressure and the ratio IRT/LVET $(r=0.9)$. With systolic time intervals the best correlation was between PEP/LVET and mean pulmonary pressure minus mean left atrial pressure $(r=0.68)$. As for the correlation of the ratio PEP/LVET and pulmonary artery diastolic pressure, $\mathbf{r}$ was found to be 0.63 (compared to 0.70 in Gutgesell's work. ${ }^{5}$

Good correlation $(0.9)$ was also found between IRT/LVET and the ratio of mean pulmonary over mean aortic pressure. This correlation has also been noted for STI, though to a lesser degree. ${ }^{5}$

In patients with d-transposition of the great arteries, frequent assessment of the pulmonary vascular resistance is of considerable clinical importance. In such patients, the risk of pulmonary arteriolar changes has been well documented, not only in the presence of ventricular septal defect ${ }^{9}$ but also with an intact septum ${ }^{23}$ and even after surgical correction by the Mustard procedure. ${ }^{24}$ From our present report, it can safely be stated that in patients with d-transposition of the great arteries a negative IRT/LVET ratio is a reliable index of normal pressure in the pulmonary circulation. Serial echocardiographic studies for the follow-up of patients with d-transposition should, therefore, always include measurement of the time of relaxation of the left ventricle in addition to currently used STI.

\section{References}

'Nanda NC, Gramiak R, Robinson TI, Shah PM. Echocardiographic evaluation of pulmonary hypertension. Circulation 1974; 50: 575-81.

${ }^{2}$ Hirschfeld S, Meyer RA, Schwartz DC, Korfhagen J, Kaplan S. The echocardiographic assessment of pulmonary artery pressure and pulmonary vascular resistance. Circulation 1975; 52: 642-50.

${ }^{3}$ Riggs T, Hirschfeld S, Borkat G, Knoke J, Liebman J. Assessment of the pulmonary vascular bed by echocardiographic right ventricular systolic time intervals. Circulation 1978; 57: 939-47.

4Johnson GL, Meyer RA, Korfhagen J, Schwartz DC, Kaplan S. Echocardiographic assessment of pulmonary arterial pressure in children with complete right bundle branch block. Am Cardiol 1978; 41: 1264-9.

${ }^{5}$ Gutgesell HP. Echocardiographic estimation of pulmonary pressure in transposition of the great arteries. Circulation 1978; 57: 1151-3.

${ }^{6}$ Gamboa A, Gersony WM, Hugenholtz PG, Nadas AS. External measurement of the isovolumic relaxation phase as an indicator of pulmonary artery pressure in ventricular septal defects. Am $\mathcal{F}$ Cardiol 1965; 16: 665-71.

${ }^{7}$ Burstin L. Determination of pressure in the pulmonary artery by external graphic recordings. $\mathrm{Br}$ Heart $\mathcal{f}$ 1967; 29: 396-404.

${ }^{8}$ Fernandez F, Scebat L, Lenègre J. Etude de la corrélation entre la durée de la phase de relaxation isométrique du ventricule droit et la pression artérielle pulmonaire. Malattie Cardiovascolari 1968; 9: 1-12.

'Newfeld EA, Paul MH, Muster AJ, Idriss FS. Pulmonary vascular disease in complete transposition of the great arteries: a study of 200 patients. $\mathrm{Am} \mathcal{F}$ Cardiol 1974; 34: 75-82.

${ }^{10}$ Parr GVS, Blackstone EH, Kirklin JW, Pacifico AD, Lauridsen P. Cardiac performance early after interatrial transposition of venous return in infants and small children. Circulation 1974; 49 and 50 Suppl. II : 2-8.

${ }^{11}$ Rowe RD. Cardiac catheterization. In: Keith JD, Rowe RD, Vlad P, eds. Heart disease in infancy and childhood. New York: Macmillan, 1978: 93.

${ }^{12}$ Lewis RP, Rittgers SE, Forester WF, Boudoulas H. A critical review of the systolic time intervals. Circulation 1977; 56: 146-58.

${ }^{13}$ Draper NR, Smith H. Selecting the 'best' regression 
equation. In: Applied regression analysis. New York: John Wiley and sons, 1966: 178.

${ }^{14}$ Weisfeldt ML, Scully $\mathrm{HE}$, Frederiksen J, et al. Hemodynamic determinants of maximum negative $\mathrm{dP} / \mathrm{dt}$ and periods of diastole. Am $\mathcal{F}$ Physiol 1974; 227: 613-21.

${ }^{15}$ Ito $M$, Fujino T, Kurata $E$, et al. Isometric contraction and relaxation times of right and left ventricles in normal subjects and in patients with right ventricular overloading measured with bidirectional echocardiography. fpn Heart f 1978; 19: 193-203.

${ }^{16}$ Cohn PE, Liedtke AJ, Serur J, Sonnenblick EH, Urschel CW. Maximal rate of pressure fall (peak negative $\mathrm{dP} / \mathrm{dt}$ ) during ventricular relaxation. Cardiovasc Res 1972; 6: 263-7.

${ }^{17}$ Arevalo F, Sakamoto T. On the duration of the isovolumetric relaxation period (IVRP) in dog and man. Am Heart $\mathcal{F} 1964$; 67: 651-6.

${ }^{18}$ Benchimol A, Ellis JG. A study of the period of isovolumic relaxation in normal subjects and in patients with heart diseases. Am f Cardiol 1967; 19: 196-206.

${ }^{19}$ Laks MM, Morady F, Garner D, Swan JC. Relation of ventricular volume, compliance, and mass in the normal and pulmonary arterial banded canine heart. Cardiovasc Res 1972; 6: 187-98.
${ }^{20}$ Pohost GM, Dinsmore RE, Rubenstein JJ, et al. The echocardiogram of the anterior leaflet of the mitral valve: correlation with hemodynamic and cineroentgenographic studies in dogs. Circulation 1975; 51 : 88-97.

${ }^{21}$ Rubenstein JJ, Pohost GM, Dinsmore RE, Harthorne JW. The endocardiographic determination of mitral valve opening and closure: correlation with hemodynamic studies in man. Circulation 1975; 51: 98-103.

${ }^{22}$ Tsakiris AG, Gordon AD, Padiyar R, Frechette D. Relation of mitral valve opening and closure to left atrial and ventricular pressures in the intact dog. Am F Physiol 1978; 234: H146-51.

${ }^{23}$ Lakier JB, Stanger P, Heymann MA, Hoffman JIE, Rudolph AM. Early onset of pulmonary vascular obstruction in patients with aortopulmonary transposition and intact ventricular septum. Circulation 1975; 51 : 875-80.

${ }^{24}$ Mair DD, Danielson GK, Wallace RB, McGoon DW. Long-term follow-up of Mustard operation survivors. Circulation 1975; 49 and 50 Suppl. II : 46-52.

Requests for reprints to Dr André Davignon, Ste Justine Hospital, 3175 Ste Catherine Road, Montreal, Quebec, Canada H3T 1 C5. 